\title{
Radical Brand Evolution: A Case-Based Framework
}

\section{BILL MERRILEES}

Griffith University, Australia

bill.merrilees@

griffith.edu.au
I would like to thank Mark Foote, president of Canadian Tire Retail (CTR), for his support of this research and for the material supplied in his RAC address (Foote, 2002). Helpful and insightful indepth interviews were held with Tracy Fellows (marketing director, CTR) and Greg Kavander (group manager, Broadcast, Events $\mathcal{E}$ Promotions, CTR). Other staff members, including Tracy Stone, manager, Consumer Research, CTR, were also helpful. The author has no financial or related relationship with the company.

The article highlights the importance of brand evolution as a necessary component of successful marketing strategy. In particular the article emphasizes the decision to revitalize the core brand. Three key constructs are used as a framework for analyzing rebranding decisions, namely brand vision, brand orientation, and brand strategy implementation. It is proposed that the key to successful rebranding is the need to build each of these three components as well as ensuring that they are tightly linked and coordinated. The normative framework was applied to a major Canadian retailer, Canadian Tire, and found to be helpful in analyzing their rebranding. Lessons have been drawn from the case study, including the important role of advertising.

All BRANDS NEED TO BE REvitAlized on a regular basis in order for them to be kept fresh, vital, and relevant to the contemporary market. Aaker (1991) and Keller (2003) each devote a chapter to this issue, but the debate is broad, lacking specific principles or theories to manage different types of brand revitalization. It is useful to refer to brand revitalization as brand evolution, as the latter conveys the impression that revitalization is continuous over time rather than a one-off minor change. We wish to focus on a particular type of brand evolution, namely radical (or revolutionary) brand evolution. Thus while brand evolution is continuous, from time to time a spike enters the trajectory, which we call a major or radical form of brand evolution. The essence of radical brand evolution is the need to take a brand forward as part of a major strategic imperative. Importantly, radical brand evolutions enable a quick, large increase in the scale of the brand, say a growth of 10 percent or more in just a year or two.

Rebranding is a major aspect of marketing and is critical for growing the brand, but there is a gap in the literature on the subject. Two earlier paradigms to brand evolution are noted and a new framework developed in this article based on case study research of a major Canadian retailer, $\mathrm{Ca}-$ nadian Tire.

\section{BRAND EVOLUTION}

One source of knowledge about radical brand evolution is case studies. Scott Bedbury was involved with the radical revitalization of two famous brands, Nike and Starbucks (Bedbury, 2002). Ironically, each of these brands had gone through a period where the brand owners simply relied on hope or intuition that other stakeholders would comprehend the brand essence meaning. The development of the Just-Do-It campaign was associated with greater definition in Nike's brand mantra toward "Authentic, Athletic, Performance." Similarly the initial fuzzy Starbuck's brand identity was transformed into "Rewarding, Everyday, Moments." In both cases Bedbury used unorthodox market research, including issues based research and monitoring for Nike and a 500-year history of coffee houses for Starbucks. The subsequent greater clarity of the brand mantra (vision) facilitated the brand alignment inside each corporation (Bedbury, 2002). Other cases could be added, but no one has used case material to formulate a general framework for brand evolution. 


\section{The essence of radical brand evolution is the need to take a brand forward as part of a major strategic imperative.}

The academic literature includes the views of Aaker and Keller that brand revitalization is an important aspect of corporate success. However there are not many explicit theories of brand evolution or rebranding. Kapferer (2001) offers more hope in his book on reinventing the brand and notes that "a brand can retain its aspirational qualities only if it continues to change and reinvent itself" (p. 222). The book does highlight the urgent need for brands to evolve, which could include consideration of relationships, values, distributors, and emotions. But no detailed blueprint for rebranding is given. Another major contribution is the work by McEnally and de Chernatony (1999) who build on the study by Goodyear (1996). A six-stage model of brand evolution is proposed, starting with unbranded goods and then evolving to "brand as reference" (with emphasis on functional differentiation), to "brand as personality" (with emphasis on emotional differentiation), to "brand as icon," to "brand as company," and finally to "brand as policy." McEnally and de Chernatony (1999) suggest that brands can enter at different stages and may not proceed through to the final destination. Indeed they suggest that stages three or four may be the apex for many companies, though the last two stages "represent the future for brands." Ikea is given as a role model for stage 5 and the Body Shop for stage 6 .

Their six-stage framework is contrasted to other dynamic branding models such as Park, Jaworski, and MacInnis (1986), in which companies choose an initial brand- ing position (functional versus symbolic), which is then managed over the brand's life cycle. In the Park, Jaworski, and MacInnis (1986) model, there is no shifting from one stage (in the Goodyear sense) to another. Both the Park-Jaworski-MacInnis and the Goodyear-McEnally-de Chernatony frameworks are recognized in Figure 1 as conceptual milestones in the development of our understanding about brand evolution. The six-stage Goodyear model will be used as part of the framework for our case study of Canadian Tire, where there is a movement from brand as icon to brand as company.

A major gap in the above models of brand evolution is that the "supply" sidethat is, the role of management in designing and implementing the new brand strategy-is not as well developed as the demand side (consumer) aspects. De Chernatony and Riley (1998) have partially redressed this gap with their double vertex model that explicitly links the two sides together. Moreover, McEnally and de Chernatony (1999) do attempt to incor-

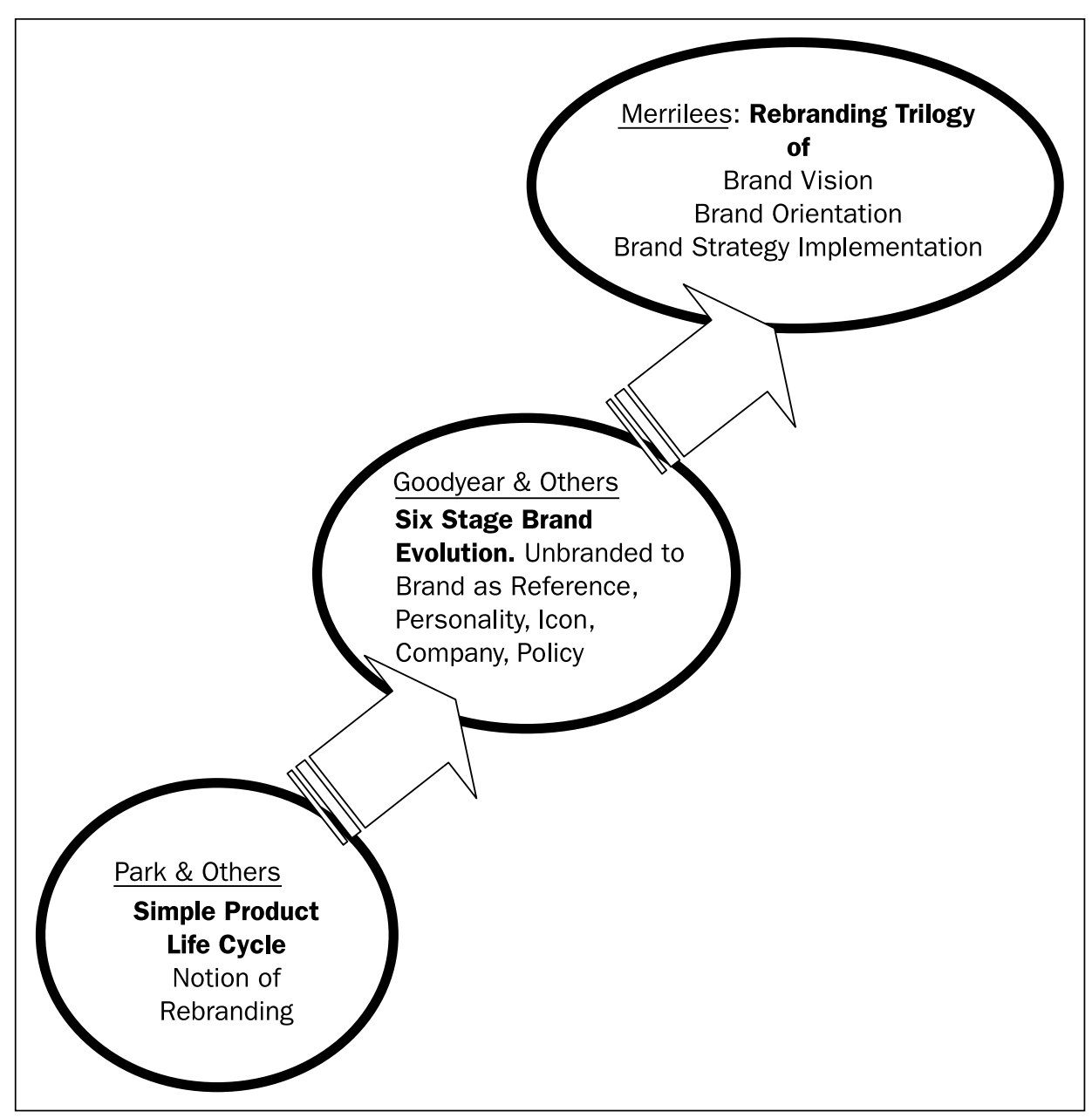

Figure 1 Evolving Conceptualization of Brand Evolution 
porate both the demand and supply aspects into their revised model of brand evolution, but there is a deliberate and strong focus on the consumer behavior interpretation of the model. All is not lost. There has been a growing literature dealing with "brand orientation," that is, the extent to which the brand becomes a central and coordinating element or core of a marketing strategy. Brand orientation occurs when the strategy is built around the brand and all parts of the organization are tied into the brand and help implement the strategy accordingly. Urde (1999, p. 117) defines brand orientation as "an approach in which the processes of the organization revolve around the creation, development and protection of brand identity in an ongoing interaction with target customers with the aim of achieving lasting competitive advantages in the form of brands." The work by Upshaw and Taylor (2000) discusses a related concept of brand commitment or masterbrand that is analogous to the brand orientation concept. That is, masterbrand is a companywide brand force "composed of a central set of associated meanings and benefits, whose scope stretches from the company's strategic core, throughout its people and partners, enveloping customers and beyond to its outer perimeter of influence" (p. 2). All of these studies see brand orientation as the responsibility of the senior executive. Wong and Merrilees (2005) elaborate on the concept of brand orientation for small- and medium-sized businesses.

The brand orientation construct has great potential as a means of establishing a framework for the supply side of brand evolution, that is, for the creation, development, and ongoing management of the brand. However for completeness we suggest that two other constructs be added, namely brand vision and brand strategy implementation. Brand vision is the (re)-

\section{Brand orientation occurs when the strategy is built around}

\section{the brand and all parts of the organization are tied into}

\section{the brand . . .}

formulation of a brand, highlighting distinctive features and values (both functional and emotional) and how the brand is positioned competitively (see de Chernatony and Riley, 1998). Brand strategy implementation is the implementation of the brand strategy through the marketing mix, including advertising. Thus the interlocking constructs of brand vision, brand orientation, and brand strategy implementation provide a new framework for tying together the demand and supply side of branding, shown in Figure 1.

In summary, the brand visionorientation-strategy implementation framework is proposed as a potentially useful theory to evaluate brand evolution. Such a framework builds on and can be used in conjunction with the six-stage model of Goodyear (1996) and McEnally and de Chernatony (1999). We propose to illustrate and "validate" the usefulness of the Goodyear and the new frameworks with an in-depth case study of the Canadian retailer, Canadian Tire.

\section{THE CASE STUDY}

Canadian Tire is a major mass merchandiser in Canada, with annual retail sales of over $\$ 6$ billion. There are about 500 associated stores operated by slightly fewer associate dealers in a relationship that resembles franchising but is not franchising. The Canadian mass merchandise market has become very competitive over the past ten years, with the arrival of Wal-Mart in 1994 (taking over Woolco), Zellers taking over Kmart in 1998, and additional pressure coming from the category killers like Home Depot and other home improvement retailers and department stores like Sears and The Bay. It is in this context that mass-merchandise retailers need to strengthen their respective brands. About mid-2001 Canadian Tire Retail (CTR) appointed a new marketing director with management responsibilities that include consumer research, retail brands, quality engineering, and loyalty programs (including Canadian Tire 'Money' ${ }^{\mathrm{TM}}$ ). An additional responsibility was CTR brand strategy and the integrity of the Canadian Tire Retail market position throughout the network.

It seems reasonable to conclude that Canadian Tire did not have a clear position in the market prior to 2001. This does not imply that it was not a strong brand, far from it. It had a strong Canadian heritage, with lots of Canadians growing up with the brand and comfortable with it (see McBride, 1997, for an internal perspective). It also had a number of wellknown product brands like Mastercraft that were well received in the market and contributed to the corporate identity. Flags and insignia bear the classic red and white Canadian colors. The sheer volume of sales would also attest to its strength as a brand. The author suggests that "brand as icon" is a way of describing the nature of the Canadian Tire brand prior to the rebranding, according to the Goodyear six-stage typology. A major strength of the company was its merchandising/advertising skills that included the powerful weekly flyer with regular specials (part of a highlow promotion strategy). Consistent with a strong merchandising culture was the belief that the company could be "all things 
to all people," which stands in contrast to the typical marketing approach of tight segmentation, targeting, and positioning. In short, the company had more of a merchandising than a marketing culture and strategy.

The new marketing director designed a brief to lead a small, five-person team to develop a new market position for the company and to guide the rebranding of the company. The team had representatives from consumer research, own labels, and advertising, with most having a marketing background. The process by which this rebranding was developed can be thought of as moving through three overlapping steps. The first step emphasized brand vision, that is, the creative research to arrive at the new market position. The second step emphasized brand orientation, that is, the need to get internal endorsement within the company from key internal stakeholders. The third step was brand strategy implementation, starting with launching the new brand, especially through advertising, and continuing to get additional internal endorsement. We will cover each of these phases in turn.

\section{Phase 1: Brand visioning}

The brand vision phase was of course crucial. The team was able to draw on past quantitative research that quickly pinpointed the target market. The primary group was parents with kids under 18 years and the secondary group was empty nesters (55 years plus). The team then turned to qualitative research, using in-depth interviews of up to two hours per consumer. A number of predetermined concepts were tested using one-line triggers to explore the nature of, meaning, and the importance that consumers attached to each concept. The exercise included the gathering of photos to elaborate on the meaning. The particular method used was based on the Zmet approach developed at Harvard Business

\section{The process by which this rebranding was developed can}

\section{be thought of as moving through three overlapping steps.}

School. Other academics have championed the role and application of in-depth qualitative research, including Zaltman and Holbrook. However the application of the $\mathrm{Zmet}$ approach in industry does not seem widespread, or at least that was the opinion of the CBC TV program Marketplace seeking to interview Canadian Tire for their use of a novel method of research.

The final product of the research was the desire of consumers to get quality products and to start new activities or tasks, such as new season, project, sport, or life event, with confidence. This led to the new market position slogan or tagline: "let's get started." This process required two essential ingredients. First, having the right assortment of quality products and knowing that they meet consumer needs. Second, the product needed to be delivered through a caring and energetic instore experience. Product and experience were the critical duo in the new market position. The market position was broader than the slogan and was not purely driven by the customer research. The consumer research interacted with intuitive desktop research using academic works that suggested how companies, especially retailers, could differentiate themselves. One particular study by Crawford and Mathews (2001) emphasized the need for retailers to be dominant on one of five broad attributes (price, product, service, access, and experience), to have a point of difference on another broad attribute, and to be competitive (at parity) on the other three attributes. The book shows that WalMart's dominance is price, with differentiation from product, while Home Depot is strongest on product with a lot of support from service. So the key point of difference for Canadian Tire was product (including its own brands), with experience the major support. In the words of the CTR president, "We love products and we love people" (Foote, 2002).

\section{Phase 2: Brand orientation process}

It is not enough to create a new brand position by projecting something different and exciting to customers. It is also necessary to get full support from all of the other internal stakeholders, including the senior executive, the dealers, the advertising agency, and the vendors. We can call this brand orientation or alternatively brand commitment, to the extent the new brand is recognized, understood, and acted upon throughout the organization and across the full gamut of business strategies. There are two main ways of involving the other internal stakeholders, either involve early or later. The later was the option chosen at Canadian Tire. A tradeoff exists. Early involvement often brings with it more passionate involvement and support in the final decision, but at a cost of greater confusion about where the new brand is heading. In retrospect the correct decision seems to have been made, in that it was a lot easier to communicate and educate a well-defined rebranding position, rather than get into embroiled in debate about vague alternatives. Even as it was, it became necessary to carefully explain the new position.

By December 2001 there was enough detail in the new market position to ensure that the advertising agency was comfortable with it and was given an advertising brief for the new campaign. The process of developing specific advertisements also had some unintended ben- 
efits in educating the executive about the new position. Merchandising-oriented executives would naturally be skeptical about a new marketing/branding-oriented position. The concrete nature of advertisements facilitated the collective understanding of what the new brand really meant in a language that nonmarketers could readily grasp and act upon. Another key milestone was a letter sent in the spring of 2002 by the president of Canadian Tire to the associate dealers, outlining and explaining the new market position and enclosing a video (including a proposed advertisement) that illustrated the new branding direction clearly. The associate dealers were of course critical internal stakeholders, so they could see that the rebranding project had the support from the highest level. Should the associate dealers have been involved at an earlier stage? There clearly was a danger of creating chaos if too many versions of the new CTR brand were rumored at the grassroots.

After the advertisements were launched, there were other opportunities to continue to educate the dealers about the new brand. For example, there were a number of special committees that included representatives from both the head office and the associate dealers. There was also an annual meeting of associate dealers in September 2002 that continued to highlight the new brand. Further, there were specific marketing programs, such as those designed to improve the "time to market" of central policy changes. These initiatives were seen as an integral part of improving the "experiential" aspects of the new brand direction. Allied to the dealers being educated was a more explicit inclusion of employees into the Canadian Tire brand. Inclusion of employees into the brand community has been successfully done by organizations like Body Shop and Wal-Mart. However, it is not as straight forward in an organization like
Canadian Tire, where employees are employed by the associate dealer rather than by the corporate office. Notwithstanding, the company broadened its mindset so that it reintroduced customer service awards for high-performing front-end staff and also included them in some advertisements. Staff training also was strengthened through an e-learning platform. Potentially the greater inclusiveness of front-end employees could have come at any time but may have been facilitated by the need for a more consistent, inclusive corporate "face" associated with the new CTR brand. A final stakeholder (other than the customer to be discussed in the phase 3 section) is that of vendors. Vendors include both suppliers of national brands as well as those contracted to make CTR retail brands. In October 2002 there was a special conference in which the vendors were briefed about the new brand and the implications for suppliers and product development. Vendors appreciated the guidance to the future demands that would be placed on them.

\section{Phase 3: Strategic brand implementation}

Launch. The official public launch of the new (revitalized) brand came with the spring 2002 television advertising campaign. This was labeled "Let's get started." The rationale of the campaign was the repositioning of the company as the retailer to help customers get started with a new season, project, sport, or life event. Related television advertising in the summer, fall, and Christmas seasons followed the spring campaign. There were variations in the specifics of the advertisements, but they were all linked to the newly positioned corporate brand. The linkages across the advertisements correspond to an integrated marketing communication (IMC) strategy. IMC is a marketing promotion tool recognized for its costeffectiveness, because it is able to get more "impact (bang) for the buck," partly from reinforcement and synthesis between and across media and partly from greater reach (see Duncan, 2002; Low, 2000). In the case at hand, the IMC was led by television advertising in each season but supported by radio, magazines, and (later in November) weekly flyers. IMC is usually discussed in the academic literature in terms of product brand campaigns, with less application to corporate rebranding campaigns.

The sequencing of the media timing in the case was important. Television advertising was the lead medium, taking on the weight of the campaign. Repetition and modified repetition of the television advertisements was important for getting the new brand image across to consumers. The other media supported, usually with a gentle or subtle reminder of the rebranding. Different media had different roles, but all were linked to a common purpose. Compared to purely product branding IMC, corporate rebranding IMC is more complex because multiple purposes need to be co-managed. This point has not previously been highlighted in the IMC literature. Apart from the common purpose of selling the new corporate brand, there was also the particular purpose of selling specific merchandise. At the beginning of the campaign, with the television advertising in particular, the former (branding) purpose was very dominant. Later, and especially with the weekly flyers, the latter (merchandising) purpose was dominant. Thus all or most of the advertising had to both sell the new brand and sell specific merchandise.

A special case of comanagement of multiple purposes was the company's demomercials. Demo-mercials are 60-second television advertisements that demonstrate new products and represent a hybrid between short television advertisements and longer infomercials. Canadian Tire had been innovative with demo- 
Repetition and modified repetition of the television advertisements was important for getting the new brand

\section{image across to consumers.}

mercials over the previous two years, sufficiently so to motivate some of their competitors to follow suit. Demo-mercials were of special significance to Canadian Tire because the brand-selling and merchandise-selling purposes were about equal. "We are product; we can help you start your new project" is integral to the new corporate brand, but equally is aligned to selling specific merchandise. The new products in the demo-mercials were often new own-brand merchandise, designed for and made on behalf of the company, such as paint with tops that allow easy pouring. Additionally, the magazine advertising was also in the demo-mercial format, reinforcing both the corporate brand and the merchandise. The comanagement of brand selling and merchandise selling added complexity to the 2002 promotion campaign. However, it also added an opportunity. Multiple detailed messages across merchandise and across seasonal uses and other situation contexts added diverse applications to a consistent corporate branding message Without this diversity of merchandise messages, the corporate message campaign might have become too repetitive and boring. The diversity of the merchandise messages required careful management, with regard to the different tempo, mood, and duration of each advertisement, as well as ensuring mental imprinting of the new corporate signature. The demo-mercials epitomized this approach to diversity.

Brand substance. Although advertising is important to communicating a new re- branding position, it is also necessary to ensure that the new brand has substance. A new corporate brand has to be more than just a slogan. For the case at hand, the substantive underpinning for the rebranding was in terms of product and in-store experience.

Product dimensions. Appropriately Canadian Tire had a "flying start" to strengthen its product platform. For the year prior to the rebranding launch, it had been slightly extending the range of its own-label merchandise. This was in categories devoid of strong national brands, so the activity did not threaten its partnerships with the national brand manufacturers. Similarly the company had been strengthening the quality controls on its own-label product specifications. Also in the period preceding the launch, the company had initiated demo-mercials, as described in the phase 2 section. Demomercials continued into and through the launch phase. Such advertisements reinforced the company's product strengths in the minds of customers. In sum, the company's practices in product ranging, quality control, and demo-mercials proceeded from prelaunch to launch, continuing to build the product platform driver of the new brand position. The vendor's conference in October 2002 was seen as a climax in this area.

Experiential dimension. In-store experience is a difficult branding component to manage for any organization. In the case of Canadian Tire, there was an added complexity, namely the reliance on execu- tion through a diverse dealer network. One key element in creating a particular type of in-store experience is store design and to that end the retailer has introduced a new generation of store format, rolled out progressively from 2003. Notwithstanding, new store diffusion is a slow, long-term process. Priority in store reformatting was given to new stores and to major refurbishments, followed by the largest stores. A second element in creating a different in-store experience was the support given to and greater involvement of the staff. This matter was discussed in the phase 2 section and included customer service awards, e-learning platforms, and staff inclusion in television advertisements. A third element in creating a more positive in-store experience was the ready availability of merchandise as needed by customers, without excessive stockouts. New internal marketing programs have been put in place to deal with these issues. A fourth and equally important element is that the new brand should provide a spiritual force that united dealers and contributes to greater consistency across the network. This is what Bedbury (2002) calls brand alignment. Although subtle and intangible in nature, this new "masterbrand" (in the Upshaw and Taylor, 2000 sense or brand orientation in the Urde, 1999 sense) is more of a "visible hand" rather than an "invisible hand" in the Adam Smith sense of a market. The more the dealers and their staff treat the brand as a "living script" (in the Macrae, 1996 sense of brand chartering) then the stronger the brand will be.

On September 27, 2002 the president of Canadian Tire Retail, Mark Foote, gave a public luncheon presentation on his company's rebranding strategy (see Foote, 2002). The audience included CTR staff, vendors to the company, the advertising agency, other retailers, the general public, and the author of this article. The presen- 
tation can be interpreted as an explanation of the new rebranding strategy to a wider set of stakeholders. The presentation outlined the objectives of greater growth and more alignment. He emphasized the need for strategy to be results driven, incorporating culture, understanding that people buy stores not product, be clearly differentiated from your competitors, and draw upon the capabilities of the company. The new Canadian Tire position was based on product as a dominant factor and in-store experience as a differentiating factor.

\section{INSIGHTS TO REBRANDING STRATEGY FROM PREVIOUS WORKS AND FROM THE CASE STUDY}

What insights would have been forthcoming from existing approaches to rebranding, and what new insights come from the new framework? The Figure 1 baseline work by Park, Jaworski, and MacInnis (1986) provides a useful prediction that brand repositioning might arise in the case of Canadian Tire because of lifecycle reasons, namely maturity and competition. The emphasis of this perspective, reinforced by Aaker and Keller, would be on consumer brand associations of the company, that is, a need to redesign the brand concept and build a stronger brand identity. In other words, nearly all of the emphasis would be on phase 1 (brand vision) of the case study, with minimal attention to phases 2 and 3 .

Moving up the hierarchy of rebranding types in Figure 1, we have the work by Goodyear (1996) and refined by McEnally and de Chernatony (1999). As discussed, this work proposes a more radical, disjunctive type of brand evolution, with six types of qualitatively very different underpinnings to brand concepts. One benefit from the Goodyear-McEnally-de Chernatony framework is assistance in classifying the initial (up to the year 2001) branding as iconic (their stage 4) and the new branding (2002 onward) as brand as company (their stage 5). Although there is still a strong emphasis on consumer associations, there is nonetheless recognition of internal considerations, including the role of staff in understanding the brand and being motivated to enhance it. Considerable insight again comes to bear through the consumer aspects of the brand repositioning, especially when there is a move to a more complex brand. However, paradoxically, the GoodyearMcEnally-de Chernatony approach does not explicitly canvass the transition from one stage to another. How does a company evolve the brand from one stage to another? The three authors discuss the different brand management issues across the six brand concept types but are silent in terms of actually moving up the ladder. Again, that is the benefit of our phases 2 and 3 of the case study and our new rebranding framework.

In summary, although earlier rebranding paradigms have a major contribution to make, it is mainly in relation to the consumer perspective and to the brand concept redevelopment, that is, phase 1 of the case study. These earlier approaches miss or underrepresent the need for ensuring that appropriate brand orientation is in place (phase 2 of the case study) and that brand strategy implementation is managed robustly (phase 3 of the case study). There is some existing literature on brand orientation and brand strategy implementation, but that is usually in the static context of the prevailing brand. The total rebranding framework proposed in this article integrates brand vision, brand orientation, and brand strategy implementation.

\section{LESSONS LEARNED: EVOLVING OUR KNOWLEDGE OF REBRANDING}

It is convenient to cluster the lessons in terms of the three components of the con- ceptual model, namely the front end (brand vision), the middle (brand orientation), and the end (brand strategy implementation). We also reflect on the lessons for the new brand vision-orientation-strategy implementation framework of rebranding, as well as the six-stage McEnally and de Chernatony (1999) model of brand evolution.

\section{The fuzzy front end (brand vision)}

Bob Cooper and others in the newproduct development (NPD) field refer to the fuzzy front-end nature of NPD. That is, the role of the consumer is an uncertain, complex, and variable component that needs to be addressed at the front end of NPD, but often handled well only in the better companies. The same might be said for new brand development because in many ways it is a cousin of NPD. For product brands it is a very close cousin, but even for multidimensional corporate brands it is still closely related. The case study highlights the importance of the creative process that clarifies and builds the brand vision. The approach at Canadian Tire combined both intuition and systematic qualitative research in a way that provided genuinely new insight into the nature and needs of their customers. It was not a "cookie cutter" quantitative market research project that was weighted toward the status quo of the brand. Instead there was a serious attempt to free thinking and reshape the nature of the brand.

Notwithstanding the transformation in the brand, there are limits in any rebranding design. In particular, although the core brand is being redesigned, the new formulation should ideally be sympathetic to the essence of the initial brand. That is, although it is necessary from time to time to radically update brands, the new variation of the brand must remain true to the initial brand. A commonly cited example of a brand that went too far was the 
1980s Coca Cola fiasco, with a forced return to Coke Classic. This raises the issues of brand integrity and authenticity, which provide the ultimate check on how far the brand can be modified. In the cases of Nike and Canadian Tire, the brand integrity and authenticity were managed satisfactorily, but not so in the case of Coke. This suggests that it is best to conduct the creative research process for radical brand evolution with real, existing customers, rather than with taste testers unconnected to the totality of the brand being tasted. In the Nike case, it was also necessary to extend this research into real, potential customers.

\section{The reflective middle (brand orientation)}

Designing a new brand vision is an important front-end task. The next step is to ensure that the new brand vision is fully accepted within the organization before launch. This stage can be conceived in terms of a number of constructs. Upshaw and Taylor (2000) refer to the notion of brand commitment in which all units in the firm are made aware and brought into alignment with the new brand. They refer to such institutional forces as brand councils, brand champions, and brand trainers. A key aspect of the negotiation phase is to recognize that there may be quite a number of internal stakeholders. The advertising agency is one that could easily be omitted, though not in the current case because of a 20-year-old relationship. One of the first priorities of negotiation is to get consensus by the executive team. Then, other internal stakeholders, including the advertising agency, dealers, employees, and vendors, can be added. Interestingly, the concrete nature of television advertisements was a unifying force in the Canadian Tire case. Notwithstanding, the communication and education process throughout the organization can be slow. There was a lag of about ten months from finalizing the advertising brief to notionally completing this phase.

\section{The reality test (brand strategy implementation)}

The sharpest part of the execution for Canadian Tire was that of advertising, starting with the spring 2002 launch of the new brand and carrying through with the complete campaign over the next two seasons. In part the sharpness of the advertising campaign was closely associated with an IMC framework; that is, the campaign was tightly linked across advertisements not only in the same medium but also across media. This was particularly evident when the author viewed the total package of television advertisements in a single viewing and then compared that with magazine and other advertisements. Of course, when the theme of an IMC is a rebranding launch, there are much greater demands on the design of such a campaign, in particular the co-management of brand selling and merchandise selling. Substance needs to accompany communication, because the success of a retail corporate rebranding strategy depends on real people having real in-store experiences to buy real products for real activities. Further endorsement came from the multitude of "fan mail" from customers following the advertisements, appreciative of the changes. Evidence of the medium-term evaluation of the brand program is given below.

\section{IMPLICATIONS FOR THE GOODYEAR MODEL}

It is not possible to comprehensively test the Goodyear model with a single case study. Nonetheless, we were able to discern a situation of radical brand evolution with one company moving from one stage to the next stage. Specifically, we interpret the brand evolution in the Canadian Tire case as moving from brand as icon to brand as company. The former brand was strongly influenced by history and the special place the brand has in the Canadian community. That basis remains but is extended with the rebranding effort to a more relationship-orientated approach to branding. Relationships cover internal ones in particular, but also those with other stakeholders including vendors and customers. Thus our case study supports (is consistent with) the six-stage model in the sense that it is useful for interpreting the observed and planned brand evolution of a particular retailer. We are not suggesting that radical brand evolution necessarily requires movement to a higher stage in the six-stage framework.

\section{IMPLICATIONS FOR THE BRAND VISION $\rightarrow$ BRAND ORIENTATION $\rightarrow$ BRAND STRATEGY IMPLEMENTATION FRAMEWORK}

We emphasize that the "new" theory is not exactly new in that the three key constructs already exist in the literature. The novel aspect of the theory is the explicit inclusion of all three constructs into a single framework. It would be a rash statement to say that a new theory could be devised and tested from a single case study. That is not our claim, except to say that the Vision $\rightarrow$ Orientation $\rightarrow$ Strategy Implementation framework looks promising. At minimum the new theory has been helpful in organizing, synthesizing, and interpreting the myriad of rebranding decisions at a particular company. This of course is the role of theory, so we can say that the evidence from this particular case study is consistent with the new framework. Thus each of the three headings provided by the framework for each of the three constructs has facilitated our understanding of each step and alerted us to possible generalizations that may apply in each component. For example, we now have a new proposition about the 
need to link customer research with a small set of management-directed options for the new brand identity. Like all good theories, it is also true that the whole is greater than the parts. That is to say, the linkages between the three components are critical and make a crucial difference to the success of the rebranding investment. All three components might be viewed as more or less of equal importance. In this respect, we can highlight the role of brand orientation because its role has often been omitted in most illustrations of brand evolution or treated in an explicit, but narrow way.

In short, the three components of vision, orientation, and strategy implementation offer a practical tool for companies to upgrade or revolutionize their brands. These three components or steps require different cognitive and relational capabilities. The first step requires clever creative skills that integrate consumer research with management intuition. The second step requires more sensitive and interactive negotiation and presentational skills. The third step demands attention to the details, particularly but not exclusively in the new brand's advertising campaign. It is critical to leverage from one step to the next. Referring to Figure 1, it is clear that the new framework provides insights not fully forthcoming with the existing paradigms of brand evolution.

\section{EVALUATION OF THE CANADIAN TIRE REBRANDING STRATEGY}

In the three years since the new brand was launched, support has continued. Indeed, the Canadian Tire executives have embraced the rebranding program. Postlaunch, a number of cross-functional workshops have been conducted across the company to introduce the new strategy, including with employees to help them in their current roles. New format stores have been progressively introduced, allowing more space to showcase products with high-impact merchandise and emphasize brand positioning, such as the start of a new season. Customer surveys suggest increased ratings in "great selection of new and different products" and "has great events that make you want to visit the store." Thus the internal evaluation of the new brand program is very supportive. In terms of external metrics, sales have grown about 4 percent per annum, with profits growing at a higher rate. These financials can be considered as very satisfactory given the increased competition and slowdown in consumer demand. The share price has doubled to $\$ 60$, also indicating success of the branding program. Both internal and external metrics are positive. Although the results are not startling, they are significant for building motivation throughout the company and for insuring that the company will survive the highly competitive environment and not be a casualty like previous major retailer rivals Kmart and Eaton's. There is scope for the company to make further gains on brand orientation and brand strategy implementation.

\section{CONCLUSIONS}

The study highlights the notion of brand evolution as a key part of business strategy, which says that all companies should factor in the necessity to change the brand from time to time, but do so in a purposeful way. Brands can evolve in different ways, either by changing the core brand or through some type of brand extension. The current article emphasizes radical changes in the core brand so that we can better understand the essential elements of what is involved with such a change. Oddly, radical brand evolution has not received a lot of attention by academics, but the six-stage model of Goodyear has been used as a helpful starting framework. Supplementing this framework is a new framework, namely the brand vision $\rightarrow$ brand orientation $\rightarrow$ brand strategy implementation rebranding model.

Both of these frameworks have been put to the test in a single case study of a major Canadian retailer, namely Canadian Tire. The six-stage model is partially supported in the sense that it helps explain the upward shift in the Canadian Tire brand concept from "brand as icon" to "brand as company." The new three-step model of brand vision-orientation-strategy implementation also proved helpful in synthesizing the process of brand evolution, ranging from brand concept design to internal stakeholder negotiations to the rebranding launch in the market place.

Together the two frameworks provide a practical platform for any company wishing to undertake a radical brand evolution, such that it becomes a step-by-step process. At the same time, the study highlights the special complexities and issues that are associated with each of the three major steps. The fuzzy front end requires the integration of management intuition with new creative consumer research. The reflective middle requires a delicate balancing of and negotiating with the interests, benefits, and costs to key internal stakeholders. Finally, the execution phase demands the best of integrated marketing communications that need to integrate corporate image and specific product offers, and ensuring that substance underpins the new brand. JAB

Bill Merrilees (Ph.D., University of Toronto) is a professor of marketing in the Department of Marketing, Griffith University, Australia. His research interests emphasize branding, strategy, and innovation.

\section{REFERENCES}

AAKer, D. Managing Brand Equity. New York: The Free Press, 1991. 
Bedbury, S. A New Brand World: Principles for Achieving Brand Leadership in the 21st Century. New York: Viking, 2002.

Crawford, F., and R. Mathews. The Myth of Excellence. New York: Crown Business, 2001.

de Chernatony, L., and F. Dall'Olmo Riley. "Modelling the Components of the Brand." European Journal of Marketing 32, 11/12 (1998): 1074-90.

Duncan, T. IMC: Using Advertising \& Promotion to Build Brands. New York: McGraw-Hill, 2002.

Foote, M. "How Well Do You Really Know Canadian Tire?" Luncheon Presentation to the Retail Advertising and Marketing Club (RAC) at the Sheraton Hotel, Toronto, Canada, September 27, 2002.
Goodyear, M. "Divided by a Common Language: Diversity and Deception in the World of Global Marketing." Journal of the Market Research Society 38, 2 (1996): 105-22.

Kapferer, Jean-Noel. Reinventing the Brand. London: Kogan Page, 2001.

Keller, K. Strategic Brand Management. Englewood Cliffs, NJ: Prentice-Hall, 2003.

Low, G. "Correlates of Integrated Marketing Communications." Journal of Advertising Research 29, 1 (2000): 27-39.

Macrae, C. The Brand Chartering Handbook. Menlo Park, CA: Addison-Wesley Longman, 1996.

McBride, H. Our Store: 75 Years of Canada and Canadian Tire. Toronto: Quantum, 1997.
McEnally, M., and L. De Chernatony. “The Evolving Nature of Branding: Consumer and Managerial Considerations." Academy of Marketing Science Review 99, 2 (1999): 1-38: [URL: www.amsreview.org/articles/mcenally02-1999. pdf].

PARK, C., B. JAWORSKI, and D. MACINNIS. "Strategic Brand Concept-Image Management." Journal of Marketing 50, 4 (1986): 135-45.

Upshaw, L., and E. TAYLOR. The Masterbrand Mandate. NewYork: John Wiley \& Sons, 2000.

Urde, M. "Brand Orientation: A Mindset for Building Brands into Strategic Resources." Journal of Marketing Management 15, 1-3 (1999): 117-33.

Wong, H., and B. Merrilees. "A Brand Orientation Typology for SMEs: A Case Research Approach." Journal of Product \& Brand Management 14, 3 (2005): 155-62. 